PHYSICAL REVIEW D 95, 039903(E) (2017)

\title{
Publisher's Note: Neutrino flux predictions for the NuMI beam [Phys. Rev. D 94, 092005 (2016)]
}

L. Aliaga, M. Kordosky, T. Golan, O. Altinok, L. Bellantoni, A. Bercellie, M. Betancourt, A. Bravar, H. Budd, M. F. Carneiro, G. A. Díaz, S. Dytman, E. Endress, J. Felix, L. Fields, R. Fine, A. M. Gago, R. Galindo, H. Gallagher, R. Gran, D. A. Harris, A. Higuera, K. Hurtado, M. Kiveni, J. Kleykamp, T. Le, E. Maher, S. Manly, W. A. Mann, C. M. Marshall, D. A. Martinez Caicedo, K. S. McFarland, C. L. McGivern, A. M. McGowan, B. Messerly, J. Miller, A. Mislivec, J. G. Morfín, J. Mousseau, D. Naples, J. K. Nelson, A. Norrick, Nuruzzaman, V. Paolone, J. Park, C. E. Patrick, G. N. Perdue, R. D. Ransome, H. Ray, L. Ren, D. Rimal, P. A. Rodrigues, D. Ruterbories, H. Schellman,

C. J. Solano Salinas, S. Sánchez Falero, B. G. Tice, E. Valencia, T. Walton, J. Wolcott, M. Wospakrik, and D. Zhang (MINERvA Collaboration)

(Received 31 January 2017; published 15 February 2017)

DOI: 10.1103/PhysRevD.95.039903

This paper was published online on 29 November 2016 with a template error resulting in the omission of an author name. The 43rd author, Nuruzzaman, has been added to the author list as of 3 February 2017. The author is not present in the printed version of the journal. 